\title{
Multifunctionality of the linker histones: an emerging role for protein-protein interactions
}

\author{
Steven J McBryant ${ }^{1}, \mathrm{Xu} \mathrm{Lu}{ }^{2}$, Jeffrey C Hansen ${ }^{1}$ \\ ${ }^{I}$ Department of Biochemistry and Molecular Biology, Colorado State University, Fort Collins, CO 80523, USA; ${ }^{2}$ Van Andel Insti- \\ tute, Grand Rapids, MI 49503, USA
}

Linker histones, e.g., H1, are best known for their ability to bind to nucleosomes and stabilize both nucleosome structure and condensed higher-order chromatin structures. However, over the years many investigators have reported specific interactions between linker histones and proteins involved in important cellular processes. The purpose of this review is to highlight evidence indicating an important alternative mode of action for H1, namely protein-protein interactions. We first review key aspects of the traditional view of linker histone action, including the importance of the H1 C-terminal domain. We then discuss the current state of knowledge of linker histone interactions with other proteins, and, where possible, highlight the mechanism of linker histone-mediated protein-protein interactions. Taken together, the data suggest a combinatorial role for the linker histones, functioning both as primary chromatin architectural proteins and simultaneously as recruitment hubs for proteins involved in accessing and modifying the chromatin fiber.

Keywords: chromatin, linker histone, higher-order structure, nucleosomes

Cell Research (2010) 20:519-528. doi:10.1038/cr.2010.35; published online 23 March 2010

The traditional view: Linker histones and chromatin fiber condensation

\section{Nucleosomes and nucleosomal arrays}

Chromosomal DNA is compacted by, and made accessible through, hierarchical levels of ordered chromatin condensation and decondensation. Chromatin is a dynamic nucleoprotein structure formed from histone proteins, DNA, and numerous chromatin-associated proteins. Nucleosomes, the fundamental building blocks of chromatin, are made up of $\sim 150$ base pairs (bp) of DNA and an octamer of core histone proteins [1]. The histone octamer consists of two molecules each of histones H2A, $\mathrm{H} 2 \mathrm{~B}, \mathrm{H} 3$, and $\mathrm{H} 4$ [2], and is stabile only when wrapped by nucleosomal DNA, or under high-salt solution conditions in vitro $[3,4]$. Approximately 1.65 superhelical turns of nucleosomal DNA are wrapped around the histone octamer to form the nucleosome, resulting in the first level of DNA condensation. The nucleosome is sta-

Correspondence: Steven J McBryant $t^{\mathrm{a}}$, Jeffrey C Hansen ${ }^{\mathrm{b}}$

Tel: +1-970-491-5440; Fax: +1-970-491-0494

aE-mail: Steven.Mcbryant@colostate.edu

${ }^{\mathrm{b}}$ E-mail: Jeffrey.c.hansen@colostate.edu bilized by extensive charge-dipole interactions between the main chains of the histones and DNA phosphates, and by hydrogen bonding between the many histone arginine residues inserted into the minor grooves of the DNA [5]. The canonical alpha-helical histone-fold motifs of the core histones (Figure 1A) bind nucleosomal DNA and make up the structured core of the nucleosome, while the N-terminal "tail" domains (NTDs) pass outside the gyres of the DNA and extend beyond the nucleosome core structure [6]. The NTDs are between 14 and 38 amino acids in length, highly basic (enriched in lysine and arginine residues), and are largely devoid of regular secondary structure [7]. The NTDs and the histone-fold domains [8] are sites of numerous, combinatorial posttranslational modifications that influence the accessibility of the nucleosomes to chromatin-associated proteins, transcription factors, and other regulatory proteins, and regulate chromatin condensation (for reviews, see [9-11]). A polymer of nucleosomes assembled on a single DNA molecule is known as a nucleosomal array. The nucleosomes in a nucleosomal array are connected by core histone-free, extra-nucleosomal DNA termed linker DNA. Linker DNA is distinguished from nucleosomal DNA in that it is not constrained in the superhelix by the 


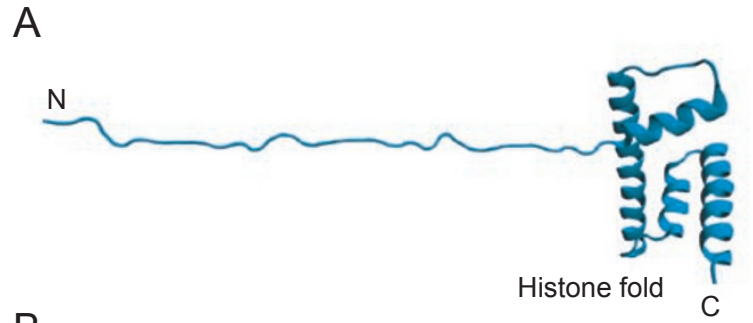

B

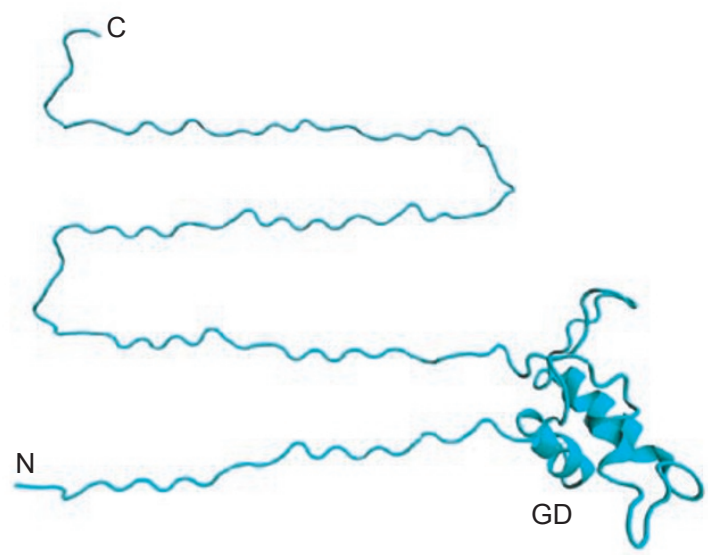

$\overline{10 \AA}$

Figure 1 The linker histone, particularly the long CTD, has the potential to mediate multiple, simultaneous interactions when bound to the nucleosome. Ribbon diagrams of the 3D structures of Xenopus laevis core histone H2B (A) and Gallus gallus linker histone $\mathrm{H} 1$ (B). Models for histones $\mathrm{H} 2 \mathrm{~B}$ and $\mathrm{H} 1$ were derived from $\mathrm{PDB}$ entries $1 \mathrm{AOI}[1]$ and the first model from entry $1 \mathrm{GHC}$ [121], respectively. The histone tails were constructed in Coot [122] by making virtual concatamers of the H2B NTD residues visible in the $\mathrm{X}$-ray structure. Images were made with the program VMD [123]. Every effort was made to ensure the C- and $\mathrm{N}$-terminal extensions were created to scale, approximately $3.5 \AA$ Á per residue for an extended peptide devoid of secondary structure.

core histones, and it is much more susceptible to nuclease digestion [12]. As will be discussed below, linker DNA possesses unique morphology in folded nucleosomal arrays and linker histone-bound chromatin fibers.

\section{Structural dynamics of nucleosomal arrays}

Nucleosomal arrays, either extracted from living cells or reconstituted from purified components, undergo a hierarchical series of salt-dependent condensation transitions [13-16]. The primary chromatin structure corresponds to an extended 'beads on a string' conformation, and is observed under very low salt concentrations (and in the absence of linker histone) [17]. When imaged under these conditions, the individual nucleosomes do not come in close contact, and the linker DNA is nearly maximally extended, with inter-nucleosome distances of 150-200 $\AA$ (this length correlates to $30-50 \mathrm{bp}$ of exposed linker DNA) $[18,19]$. The addition of salts (e.g., $1-2 \mathrm{mM} \mathrm{MgCl}_{2}$ or $100-200 \mathrm{mM} \mathrm{NaCl}$ [20]) causes shortrange, intra-array nucleosome-nucleosome interactions, resulting in folding of the array into secondary chromatin structures. The endpoint of salt-dependent folding of arrays is widely thought to be the canonical $30-\mathrm{nm}$ fiber described in early physical studies of fragmented chromatin and also observed more recently using model systems $[12,14,15,21-23]$ (for reviews, see [24-27]). The nature of the structure of the $30-\mathrm{nm}$ fiber itself has been studied and debated at length, yielding two basic models (for reviews, see $[21,25,26])$. A two-start helix, consisting of a zig-zag arrangement of stacked nucleosomes, with 5-6 nucleosomes per 11-nm helical rise, was proposed based on biochemical [23] and crystallographic data obtained with a tetranucleosome array having a very short nucleosome repeat length $(167 \mathrm{bp})$ in the absence of linker histone [28]. This was reinforced by EM of cross-linked arrays and computer modeling [29]. In this study, both simulated and formaldehyde cross-linked EM structures were used to determine internucleosome connectivities. The dominant connectivities in both simulated and crosslinked arrays were found to be between nucleosomes $\mathrm{N}$ and $\mathrm{N} \pm 2$, though, importantly, the addition of magnesium ions raised the proportion of nearest neighbor $(\mathrm{N} \pm 1)$ and $\mathrm{N} \pm 3$ contacts, indicative of (linker) DNA bending to accommodate greater compaction. These data were thus found to be consistent with the two-start, zig-zag, twisted ribbon model.

Alternatively, EM studies of long polynucleosome arrays of varying repeat length, in the presence and absence of linker histone and salt, have provided convincing evidence for the one-start, interdigitated solenoid structure, with $\sim 11$ nucleosomes per $11-\mathrm{nm}$ rise [30, 31]. This structure requires $\sim 6$ consecutive nucleosomes containing linker histone in order to complete one helical turn, and thus, the structure is stabilized through $\mathrm{N}$ \pm 6 connections. This work supports early work using endogenous chromatin fragments purified from chicken erythrocyte nuclei, where neutron scattering supported the notion that linker histone was essential for forming the 30-nm fiber [32]. A more recent study using magnetic tweezers to pull on long 197-bp repeat length nucleosome arrays, and comparing arrays with and without linker histone, suggests that based upon the slopes of the stretching curves the arrays respond in a manner consistent with Hooke's law; thus, the structure must be solenoidal, not zig-zag [33]. Shorter repeat length arrays (167 $\mathrm{bp}$, more similar to the studies from the Richmond lab 
$[23,28])$ are shorter and stiffer when folded, consistent with the two-start helix. Thus, nucleosome repeat length is a predictor of the specific, perhaps local, higher-order structure of the 30-nm fiber.

At a slightly higher concentration of divalent salt than those that induce folding, nucleosomal arrays reversibly self-associate into tertiary chromatin structures. This structural transition was observed in the earliest studies of chromatin, as dating back over 50 years ago it was reported that isolated rat and chicken nuclei underwent a reversible and cooperative transition from a homogenous to granular state when the buffer included $5 \mathrm{mM} \mathrm{MgCl} 2$ [34-37]. Nucleosomal array model systems and homogenous, recombinant core histone octamers have been used to extensively characterize the self-association transition $[20,38,39]$. The use of octamers in which the NTDs had been removed through recombinant DNA techniques [40] showed that the NTDs of H2A, H2B, H3 and H4 contribute additively and independently to nucleosome array oligomerization. Collectively, nucleosomal array folding and self-association are correlated with short-range folding and long-range fiber-fiber interactions, respectively, present in eukaryotic interphase chromosome fibers $[14,16]$.

\section{Linker histones}

The folded secondary structures formed by nucleosomal arrays at physiological ionic strength are intrinsically unstable and require other proteins to "lock" the arrays into stable higher-order secondary chromatin structures [14]. These proteins have been termed chromatin architectural proteins [41]. The most abundant chromatin architectural proteins in higher eukaryotes are the linker histones, a family of proteins structurally distinct from the core histones. Unlike the highly evolutionarily conserved core histones, which most likely evolved from an archebacterial ancestor [42], the sequences of the linker histone variants are more highly variable across species (for a review, see [43]) and are thought to have evolved from eubacteria [44]. Linker histones are present at an average of nearly one molecule per nucleosome in living cells $[45,46]$, less in species with shorter nucleosome repeat length. The stoichiometry is closer to one molecule per nucleosome in highly condensed heterochromatin, and somewhat lower in decondensed euchromatin [46]. A nucleosome bound by linker histones is called a chromatosome, while a nucleosome array assembled with linker histones is called a chromatin fiber. For the purpose of simplicity, within this review we will focus on linker histone $\mathrm{H} 1$ and its sequence variants (for a review, see [47]).

Linker histones have a tripartite structure unlike that of the core histones (Figure 1B), with unstructured N-
(13-40 amino acids in length) and C-terminal ( 100 amino acids) domains flanking a well-folded 'globular domain' (GD) of $\sim 80$ amino acids [48]. No specific function has been observed for the NTD; thus, its nature remains largely enigmatic. The structure of the central, globular domain [49-51] contains at least two separate DNA-binding sites: the first involves a classical wingedhelix motif and the second a cluster of conserved basic residues on the opposite face of that domain [51]. These two DNA-binding domains allow the linker histone globular domain to bridge different DNA molecules and form tram-track structures [52], and explain the preferential binding of linker histone to DNA crossovers [53] and four-way junctions [54]. Linker histones asymmetrically bind to the nucleosomes of chromatin fibers at the nucleosomal DNA entry and exit sites [55-58] and increase the micrococcal nuclease protection of nucleosomes from 146 to $\sim 168$ bp [59].

\section{Linker histones and the structural dynamics of chromatin fibers}

Early studies of native chromatin fibers revealed distinct differences in the fiber morphology when stripped of linker histone to form nucleosomal arrays [17, 60]. Specifically, H1-containing chromatin fibers had a more regular helical appearance. On the other hand, the addition of salt caused "clumping", not formation of the defined fibers of regular diameter seen in H1-containing fibers. Thus, it was proposed that $\mathrm{H} 1$ must be bound near the entry-exit sites to alter the DNA paths and "induce" folding of chromatin fiber into regular 30-nm diameter structures. As discussed above, many studies have established that nucleosomal arrays in salt equilibrate between extended and highly folded conformations. Three decades after the original research, we now know that the effects of linker histones are to (1) convert a heterogeneous population of folded nucleosomal arrays into stable 30-nm diameter structure(s), and (2) cause chromatin fibers to self-associate at much lower salt concentrations than nucleosomal arrays. These and related results have been interpreted to mean that linker histones stabilize the intrinsic condensed structures formed by nucleosomal arrays $[13,20,61]$. Similar conclusions have been derived from recent single-molecule magnetic tweezer studies [33]. Of note, H1-dependent formation of stable 30-nm structures is cooperative [30] and dependent on the linker histone being bound to 5-7 contiguous nucleosomes [32]. In addition to the stabilizing function, there seems to be little doubt that linker histones promote increased compaction and regularity of the $30-\mathrm{nm}$ structures [30]. Thus, linker histones both stabilize the folded fiber and induce specific structural features such as the stem-loop motif 
described below.

The mechanism through which the linker histones influence chromatin folding has been investigated using both conventional and cryo-electron microscopy to image linker histone-containing trinucleosome fragments from chicken erythrocytes [62]. These studies resulted in particularly high-resolution images of a 3D zig-zag conformation showing that linker histones decrease the entry-exit angle of DNA from the nucleosome. In addition, the entering and exiting DNA strands were seen to emerge tangentially from a single origin close to the nucleosome when the linker histone was present. This close approach of the entry-exit DNA is known as a stem or apposed stem motif, and has been studied in great detail by the Woodcock lab and others [62-64]. The three possible orientations of the entry-exit DNA are such that the DNA linking number changes to -2 (the strands cross), -1 (the strands come to parallel, then diverge), or 0 (the strands cross one another and cross the nucleosome). In order to bring the entry-exit strands this close, sufficient screening of the DNA negative charge is likely provided by the large number of positively charged amino acids in the linker histone CTD (and possibly the H3 NTD [65]).

The H1 CTD has been directly implicated in chromatin folding: fibers bound to a proteolytically truncated H1 lacking the CTD were not capable of stabilizing 30$\mathrm{nm}$ diameter secondary chromatin structures $[66,67]$. The amino acid composition ( $40 \%$ Lys and Arg, $<10 \%$ hydrophobic residues) of the CTD is ideal for allowing ionic interactions of a largely extended domain with the linker DNA. In addition, alternating Lys and Ala residues interspersed with Pro create a uniform charge distribution [68] predisposed to form proline-kinked $\alpha$-helical elements [69]. Two recent papers investigating the role of the H1 CTD in chromatin condensation have provided surprising insight into how this domain functions. In the first paper, the folding and self-association dynamics of chromatin fibers bound to a series of mouse H1-0 CTD truncation mutants were determined. The results indicated that there are two discontinuous "sub-domains" within the CTD that mediate H1 function in stabilizing the condensed chromatin [70]. These sub-domains are defined by residues 97-121 (which directly abut the globular domain) and 145-169. Residues 122-144 and 170-196 could be deleted without affecting the function. In the second paper, the role of the unique CTD aminoacid composition [71] was determined by studying the $\mathrm{H} 1$ isoforms and performing sub-domain swapping and directed mutagenesis experiments [72]. Results showed that the $\mathrm{H} 1$ isoforms, which vary significantly in their primary sequence but not in their amino-acid composition, all functioned identically in chromatin condensa- tion assays in vitro. Randomization of amino acids 97121, while maintaining the unique H1 CTD amino-acid composition, had no effect on condensation transitions, ruling out primary sequence as a determinant of function. Surprisingly, sub-domain "swap" mutants, in which residues 122-144 and 170-196 replaced residues 97121 , functioned as well as wild-type protein in mediating chromatin condensation pathways. These results indicate that the molecular determinants of H1 CTD function in chromatin condensation are its unique amino-acid composition and the specific location of sub-domains of the CTD relative to the globular domain, not its primary sequence.

The determinants of H1 CTD function have been linked to intrinsic protein disorder [72]. Intrinsically disordered protein domains lack native structure but often undergo a disorder-to-order transition concomitant with binding to nucleic acids or other proteins [71, 73, 74]. There is substantial evidence that the H1 CTD is intrinsically disordered. The CTD and peptides derived from the CTD are random coils in aqueous solution [75, 76]. Trifluoroethanol increases the $\alpha$-helical content of the CTD, as does sodium perchlorate, indicating that the CTD has an inherent propensity to form $\alpha$-helical structures. Importantly, a peptide corresponding to residues 99-121 of the H1 CTD becomes $\alpha$-helical upon binding to DNA $[77,78]$. This peptide closely corresponds to the functional domain that abuts the $\mathrm{H} 1$ globular domain and was shown to be important for chromatin condensation (see above, and [70]). Most recently, the full-length H1 CTD was studied in a variety of solution conditions in the presence and absence of DNA, and was shown to adopt a full complement of secondary stuctures [79]. Taken together, these data suggest that the CTD mediates stabilization of condensed chromatin fibers by assuming $\alpha$-helical and/or $\beta$-strand structure(s) upon binding to linker DNA. As we will see below, intrinsic disorder also appears to play a role in some CTD-mediated proteinprotein interactions.

\section{The emerging view: Linker histones and protein- protein interactions}

\section{Linker histones bind many different nuclear and cyto- solic proteins}

The previous sections describe the traditional, wellestablished functions of $\mathrm{H} 1$ as a chromatin architectural protein. However, increasing evidence has accumulated indicating that linker histones also act by interacting with many different non-histone nuclear and cytosolic proteins. Specifically, at least 16 examples of linker histoneprotein interactions can be found scattered throughout 
the literature (summarized in Table 1). Taken together, the data in Table 1 clearly indicate that $\mathrm{H} 1$ functions in part by participating in protein-protein interactions. It is therefore appropriate to ask: how many more H1interacting proteins remain to be identified? Two groups have recently utilized distinct approaches to examine H1protein interactions in vivo. Fang-Lin Sun and co-work- ers [80] used antibodies against the $\mathrm{N}$ - and C-terminal regions of H1 to co-IP nuclear proteins from Drosophila melanogaster Kc cells. What they identified as H1-binding proteins include $\mathrm{H} 2 \mathrm{~B}$ and $\mathrm{H} 3,40 \mathrm{~S}$ and $60 \mathrm{~S}$ ribosome components, and two proteins (hnRNP48 and hnRNP36) involved in pre-mRNA processing and cytoplasmic export $[81,82]$. However, they identified only "the most

Table 1 Specific H1-protein interactions

\begin{tabular}{|c|c|c|c|}
\hline H1 binding partner & Method(s) & Proposed function(s) & Reference \\
\hline HuSirT1 & $\begin{array}{l}\text { Pull-out from FlagSirT1- } \\
\text { expressing cells in vivo; } \\
\text { pull-down in vivo }\end{array}$ & $\begin{array}{l}\text { HuSirT1-H1 interaction targets histone deacetylase to } \\
\text { H4K16 }{ }^{\mathrm{Ac}} \text { promoters, i.e., active genes, encouraging } \\
\text { chromatin condensation }\end{array}$ & [109] \\
\hline $\begin{array}{l}\text { Prothymosin } \alpha \\
\text { (ProT } \alpha)\end{array}$ & Blotting assays; co-IP & $\begin{array}{l}\text { ProT } \alpha \text { sequesters H1 from chromatin, thus up-regulating } \\
\text { genes involved in cellular proliferation }\end{array}$ & {$[100,110]$} \\
\hline $\begin{array}{l}\text { Lysyl oxidase } \\
\text { (LOX) }\end{array}$ & $\begin{array}{l}\text { Blotting assays; affinity } \\
\text { purification }\end{array}$ & $\begin{array}{l}\text { LOX might deaminate lysines on histones and alter } \\
\text { chromatin structure similar to acetylation }\end{array}$ & [113] \\
\hline $\begin{array}{l}\text { CaM kinase II } \\
\text { (CaMKII) }\end{array}$ & Enzymatic inhibition assays & $\begin{array}{l}\text { H1 inhibits CaMKII activity via calmodulin; inhibition } \\
\text { is reversed by DNA }\end{array}$ & {$[114]$} \\
\hline $\begin{array}{l}\text { Protein kinase } \\
\mathrm{C} \varepsilon(\mathrm{PKC} \varepsilon \varepsilon)\end{array}$ & $\begin{array}{l}\text { Blotting assays; kinase } \\
\text { activity assays }\end{array}$ & $\begin{array}{l}\text { H1 may anchor PKCE to promoter-specific chromatin } \\
\text { regions and regulate gene expression }\end{array}$ & [117] \\
\hline $\begin{array}{l}\text { Heterochromatin } \\
\text { protein } 1(\mathrm{HP} 1)\end{array}$ & $\begin{array}{l}\text { Pull-downs, affinity colu- } \\
\text { mns in vitro }\end{array}$ & $\begin{array}{l}\text { HP1 recruitment to condensed chromatin and establi- } \\
\text { shment of condensed heterochromatin }\end{array}$ & {$[98,99]$} \\
\hline HMG1 & Fluorescence spectroscopy & $\begin{array}{l}\text { HMG1/2 and } \mathrm{H} 1 \text { compete for binding to linker DNA, } \\
\text { thereby affecting chromatin structure }\end{array}$ & [118] \\
\hline $\begin{array}{l}\text { Barrier to autoin- } \\
\text { tegration factor } \\
\text { (BAF) }\end{array}$ & $\begin{array}{l}\text { Blotting assays; microtiter } \\
\text { binding assays; co-IP }\end{array}$ & $\begin{array}{l}\text { H1.1 binding may direct viral integration to open, active } \\
\text { chromatin }\end{array}$ & {$[95]$} \\
\hline $\begin{array}{l}\text { Poly ADP-ribose } \\
\text { polymerase } 1 \\
\text { (PARP1) }\end{array}$ & $\begin{array}{l}\text { Pull-out from FlagH1.2- } \\
\text { expressing cells in vivo; } \\
\text { co-IP; fluorescence }\end{array}$ & $\begin{array}{l}\text { Cooperation between two proteins involved in chromatin } \\
\text { condensation }\end{array}$ & {$[83,84]$} \\
\hline $\begin{array}{l}\text { Nuclear autoantigenic } \\
\text { sperm protein (NASP) }\end{array}$ & $\begin{array}{l}\text { Native protein EMSA; } \\
\text { affinity purification; } \\
\text { surface plasmon resonance } \\
\text { (SPR) }\end{array}$ & H1 "chaperone" that deposits H1 onto nucleosome arrays & {$[119,120]$} \\
\hline DFF40 & Affinity column/blot; EMSA & $\begin{array}{l}\text { H1-mediated activation of chromatin fragmentation by } \\
\text { DFF40 is a key step in apoptosis }\end{array}$ & {$[91,94]$} \\
\hline
\end{tabular}


prominent bands present between 15 and $50 \mathrm{kDa}$ in the gels", and thus many other interesting H1-binding proteins may have been present and not accounted.

The work from the lab of Woojin An [83] provides more direct insight into the breadth of interactions in which $\mathrm{H} 1$ is involved. Using a cell line stably expressing a tandem-tagged H1.2 construct (Flag-HA-H1.2), a series of separation steps (P-11 phosphocellulose and M2 agarose chromatography, glycerol gradient sedimentation) and mass spectrometry were used to identify the binding partners. A stained SDS-PAGE gel demonstrates the presence of nearly 20 prominent bands and many other less abundant stained bands, strongly suggesting that the number of H1-specific binding partners is much larger than indicated in Table 1. In terms of specific proteins, a protein kinase (DNA-PK) and phosphatase (PP1), PolyADP-Ribose Polymerase 1 (PARP1) [84], cell-survival transcription factor YB1 [85], and the DNA/RNA binding protein PUR $\alpha$ [86] were identified.

\section{Mechanisms of linker histone-protein interactions}

As with chromatin condensation, it is of interest to know which linker histone domain(s) mediate proteinprotein interactions and the mechanism(s) through which they act. The most thoroughly described interaction at the molecular level involves the apoptotic nuclease DNA Fragmentation Factor, DFF40 (for reviews, see [87, 88]). DFF40 exists in the nucleus in complex with its chaperone and inhibitor DFF45 [89] [caspase-activated DNase (CAD) and inhibitor of CAD in mice]. DFF45 is cleaved at two caspase- 3 sites late in the apoptotic pathway, releasing DFF40 from the DFF40/DFF45 dimer and allowing DFF40 to form enzymatically active homo-oligomers [90-92]. Free DFF40 is highly specific and active in cleaving the linker DNA between nucleosomes, in the process releasing small chromatin fragments. Because of its preference for linker DNA, it was soon discovered that DFF40-dependent DNA cleavage was greatly stimulated by linker histones [89, 91, 93].

A detailed biochemical analysis subsequently investigated the mechanism of DFF40-linker histone interactions [94]. The first unexpected observation was that the H1 CTD mediated the protein-protein interaction. Using the same H1-0 mutants as Lu and Hansen [70], it was shown that progressive deletion of the 72 most Cterminal residues of the H1 CTD led to progressive loss of DFF40-dependent DNA cleavage. Of note, no further effect was observed when the 24-residue region immediately abutting the globular domain was deleted. Thus, the regions of the CTD needed to mediate chromatin condensation and DFF40 interactions appear to be distinct. The CTD also functioned independently of the rest of the protein; a number of different 48-residue peptides derived from the H1 CTD led to activation levels similar to those of full-length H1. Interestingly, the aminoacid composition of all the activating peptides was very similar. Consistent with this observation, six of the mouse somatic $\mathrm{H} 1$ isoforms, which differ significantly in their primary sequence but not amino-acid composition, activated DFF40 equally well. Thus, amino-acid composition appears to be an important determinant of H1-DFF40 interactions in addition to H1-chromatin interactions. These studies further showed that DFF40-H1 interactions enhanced DNA binding by DFF40, and that incubation of DFF40 with the isolated H1 CTD or any of the $\sim 48$ amino-acid peptides significantly enhanced DNA binding, similar to the effect on DNA cleavage. The binding of $\mathrm{H} 1$ to the barrier to autointegration factor (BAF) protein is also dependent on the H1 CTD [95], although mechanistic studies of the BAF-H1 interaction were not performed. Taken together, these results support the conclusion that the H1 CTD is capable of mediating interactions with both DNA and specific proteins, thus implicating the CTD as an important determinant of linker histone multifunctionality.

Unfortunately, the majority of studies of H1-dependent protein-protein interactions described have not distinguished whether the GD, NTD, or CTD is responsible for the interaction. The H1 CTD can form an amphipathic (basic residues on one face, hydrophobic residues on the opposing face) $\alpha$-helix [78], and thus contains a hydrophobic surface, possibly utilized for protein binding. Further, it has been shown that the H1 NTD (residues 11-23, which abut the GD) can form a non-amphipathic $\alpha$-helix [96]. As no chromatin-condensing function has been ascribed to the NTD, perhaps this is also a site of H1-protein interactions, as suggested for Msx-1 [97] and HP1 $[98,99]$.

Prothymosin (ProT $\alpha$ ) co-IPs with H1, is able to extract a fraction of $\mathrm{H} 1$ from reconstituted chromatin, and gel shifts both the full-length $\mathrm{H} 1$ and the globular domain [100]. ProT $\alpha$ is small (12 kDa), highly acidic, and predicted to be largely unstructured. The interaction with the GD is intriguing, as is the observation that ProT $\alpha$ interferes with $\mathrm{H} 1$-chromatin binding, since $\mathrm{H} 1$ binding to nucleosomes occurs in part through the GD. However, none of the assays looked for contacts with the linker histone CTD or NTD, and in light of the biochemical nature of ProT $\alpha$, it seems possible that the basic, unstructured H1 CTD may be able to interact with the highly acidic ProT $\alpha$. Similar hypotheses can be made for parathymosin, which biochemically is a nearly identical protein to ProT $\alpha$.

While we can now say with some certainty that H1 
functions in part through protein-protein interactions, much more work will be necessary to define the extent to which the three linker histone domains function as protein-protein interfaces. However, in view of what little is known, it seems likely that all three domains are able to serve in this role depending on the specific proteinprotein interaction in question.

\section{Linker histone post-translational modifications and protein-protein interactions}

The $\mathrm{H} 1$ isoforms are phosphoproteins, as numerous serine and threonine residues in the $\mathrm{N}$ - and $\mathrm{C}$-terminal domains are phosphorylated in response to various cellular stimuli [101-105]. More recent proteomic approaches have uncovered additional and specific combinations of modifications besides phosphorylation, such as ubiquitylation [106], lysine acetylation [107], and lysine methylation (for excellent reviews, see [101, 108]). One intriguing example involving protein-protein interactions comes from the Schneider lab, who determined that the chromodomain of the protein HP1 specifically recognizes methylated lysine $26\left(\mathrm{~K} 26^{\mathrm{Me}}\right)$ of $\mathrm{H} 1$ isoform 1.4 [99]. Of note, phosphorylation of the adjacent serine $27\left(\mathrm{~S} 27^{\text {Phos }}\right)$ blocked binding of HP1, creating an on-off switch for HP1 binding. Interestingly, a more recent study from the Reinberg lab showed that the mono- or di-methylation of $\mathrm{H} 1$ lysine $26\left(\mathrm{~K} 26^{\mathrm{Me} / \mathrm{Me}}\right)$ leads to binding of a different chromatin-condensing protein (L3MBTL1) at $\mathrm{Rb}$ regulated genes [27], again establishing a link between post-translational modifications of the H1 NTD and H1mediated protein-protein interactions. Such specific, post-translational modification-controlled recruitment of H1 by a heterochromatin-specific protein such as HP1 acting through $\mathrm{H} 1 \mathrm{~N}$-terminal residues indicates a function other than nucleosomal DNA binding for the linker histone NTD.

\section{Concluding remarks}

It is clear from both the large number of specific H1dependent protein-protein interactions, and the cellular processes with which these $\mathrm{H} 1$ interacting proteins are involved, that the linker histones are much more than just a nucleosome-binding protein that stabilizes higher-order chromatin structures. Rather, it appears that $\mathrm{H1}$ also is a multifunctional recruitment hub for a number of overlapping (and often opposing) processes centered on the genomic DNA. It is interesting that many of interactions are with proteins thought to be primarily localized to the cytosol. In the future, more effort needs to be focused on determining the full breadth of H1-mediated proteinprotein interactions, as well as on mapping the domains responsible and identifying the mechanisms through which they act. This will lead to clarification of the many gaps in our current understanding of the molecular basis for the multifunctional nature of the linker histone family.

\section{Acknowledgments}

This work was supported by National Institutes of Health grant GM45916 to JCH.

\section{References}

1 Luger K, Mader AW, Richmond RK, Sargent DF, Richmond TJ. Crystal structure of the nucleosome core particle at $2.8 \mathrm{~A}$ resolution. Nature 1997; 389:251-260.

2 Burlingame RW, Love WE, Wang BC, Hamlin R, Nguyen HX, Moudrianakis EN. Crystallographic structure of the octameric histone core of the nucleosome at a resolution of $3.3 \mathrm{~A}$. Science 1985 ; 228:546-553.

3 Thomas JO, Butler PJ. Characterization of the octamer of histones free in solution. J Mol Biol 1977; 116:769-781.

4 Ruiz-Carrillo A, Jorcano JL. An octamer of core histones in solution: central role of the H3-H4 tetramer in the self-assembly. Biochemistry 1979; 18:760-768.

5 Luger K, Richmond TJ. DNA binding within the nucleosome core. Curr Opin Struct Biol 1998; 8:33-40.

6 Luger K, Richmond TJ. The histone tails of the nucleosome. Curr Opin Genet Dev 1998; 8:140-146.

7 Hansen JC, Tse C, Wolffe AP. Structure and function of the core histone N-termini: more than meets the eye. Biochemistry 1998; 37:17637-17641.

8 Mersfelder EL, Parthun MR. The tale beyond the tail: histone core domain modifications and the regulation of chromatin structure. Nucleic Acids Res 2006; 34:2653-2662.

9 Cedar H, Bergman Y. Linking DNA methylation and histone modification: patterns and paradigms. Nat Rev Genet 2009; 10:295-304.

10 Lennartsson A, Ekwall, K. Histone modification patterns and epigenetic codes. Biochim Biophys Acta 2009; 1790:863-868.

11 Shukla A, Chaurasia P, Bhaumik SR. Histone methylation and ubiquitination with their cross-talk and roles in gene expression and stability. Cell Mol Life Sci 2009; 66:1419-1433.

12 Van Holde K. Chromatin. New York: Springer-Verlag, 1988.

13 Garcia-Ramirez M, Dong F, Ausio J. Role of the histone "tails" in the folding of oligonucleosomes depleted of histone H1. $J$ Biol Chem 1992; 267:19587-19595.

14 Hansen JC. Conformational dynamics of the chromatin fiber in solution: determinants, mechanisms, and functions. Annu Rev Biophys Biomol Struct 2002; 31:361-392.

15 Woodcock CL, Dimitrov S. Higher-order structure of chromatin and chromosomes. Curr Opin Genet Dev 2001; 11:130135.

16 Lu X, Klonoski JM, Resch MG, Hansen JC. In vitro chromatin self-association and its relevance to genome architecture. Biochem Cell Biol 2006; 84:411-417.

17 Thoma F, Koller T, Klug A. Involvement of histone H1 in the organization of the nucleosome and of the salt-dependent superstructures of chromatin. J Cell Biol 1979; 83:403-427. 
18 Varshavsky AJ, Bakayev VV, Georgiev GP. Heterogeneity of chromatin subunits in vitro and location of histone H1. Nucleic Acids Res 1976; 3:477-492.

19 Whitlock JP, Jr, Simpson RT. Removal of histone H1 exposes a fifty base pair DNA segment between nucleosomes. Biochemistry 1976; 15:3307-3314.

20 Schwarz PM, Felthauser A, Fletcher TM, Hansen JC. Reversible oligonucleosome self-association: dependence on divalent cations and core histone tail domains. Biochemistry 1996; 35:4009-4015.

21 Robinson PJ, Rhodes D. Structure of the '30 nm' chromatin fibre: a key role for the linker histone. Curr Opin Struct Biol 2006; 16:336-343.

22 Wolffe A. Chromatin: Structure and Function. 3rd Edition. San Diego: Academic Press, 1998.

23 Dorigo B, Schalch T, Kulangara A, Duda S, Schroeder RR, Richmond TJ. Nucleosome arrays reveal the two-start organization of the chromatin fiber [see comment]. Science 2004; 306:1571-1573.

24 Kornberg RD. The molecular basis of eukaryotic transcription. Proc Natl Acad Sci USA 2007; 104:12955-12961.

25 Staynov DZ. The controversial $30 \mathrm{~nm}$ chromatin fibre. Bioessays 2008; 30:1003-1009.

26 Tremethick DJ. Higher-order structures of chromatin: the elusive $30 \mathrm{~nm}$ fiber. Cell 2007; 128:651-654.

27 Trojer P, Reinberg D. Facultative heterochromatin: is there a distinctive molecular signature? Mol Cell 2007; 28:1-13.

28 Schalch T, Duda S, Sargent DF, Richmond TJ. X-ray structure of a tetranucleosome and its implications for the chromatin fibre. Nature 2005; 436:138-141.

29 Grigoryev SA, Arya G, Correll S, Woodcock CL, Schlick T. Evidence for heteromorphic chromatin fibers from analysis of nucleosome interactions. Proc Natl Acad Sci USA 2009; 106:13317-13322.

30 Routh A, Sandin S, Rhodes D. Nucleosome repeat length and linker histone stoichiometry determine chromatin fiber structure. Proc Natl Acad Sci USA 2008; 105:8872-8877.

31 Robinson PJ, Fairall L, Huynh VA, Rhodes D. EM measurements define the dimensions of the "30-nm" chromatin fiber: evidence for a compact, interdigitated structure. Proc Natl Acad Sci USA 2006; 103:6506-6511.

32 Graziano V, Gerchman SE, Ramakrishnan V. Reconstitution of chromatin higher-order structure from histone H5 and depleted chromatin. J Mol Biol 1988; 203:997-1007.

33 Kruithof M, Chien FT, Routh A, Logie C, Rhodes D, van Noort J. Single-molecule force spectroscopy reveals a highly compliant helical folding for the 30-nm chromatin fiber. Nat Struct Mol Biol 2009; 16:534-540.

34 Anderson NG, Wilbur KM. Studies on isolated cell components. IV. The effect of various solutions on the isolated rat liver nucleus. J Gen Physiol 1952; 35:781-796.

35 Brasch K, Seligy VL, Setterfield G. Effects of low salt concentration on structural organization and template activity of chromatin in chicken erythrocyte nuclei. Exp Cell Res 1971; 65:6172.

36 Philpot JS, Stanier JE. The choice of the suspension medium for rat-liver-cell nuclei. Biochem $J$ 1956; 63:214-223.

37 Ris H, Mirsky AE. The state of the chromosomes in the interphase nucleus. J Gen Physiol 1949; 32:489-502.
38 Kan PY, Caterino TL, Hayes JJ. The H4 tail domain participates in intra- and internucleosome interactions with protein and DNA during folding and oligomerization of nucleosome arrays. Mol Cell Biol 2009; 29:538-546.

39 Kan PY, Lu X, Hansen JC, Hayes JJ. The H3 tail domain participates in multiple interactions during folding and self-association of nucleosome arrays. Mol Cell Biol 2007; 27:20842091.

40 Gordon F, Luger K, Hansen JC. The core histone N-terminal tail domains function independently and additively during saltdependent oligomerization of nucleosomal arrays. J Biol Chem 2005; 280:33701-33706.

41 McBryant SJ, Adams VH, Hansen JC. Chromatin architectural proteins. Chromosome Res 2006; 14:39-51.

42 Reeck GR, Swanson E, Teller DC. The evolution of histones. $J$ Mol Evol 1978; 10:309-317.

43 Izzo A, Kamieniarz K, Schneider R. The histone H1 family: specific members, specific functions? Biol Chem 2008; 389:333-343.

44 Kasinsky HE, Lewis JD, Dacks JB, Ausio J. Origin of H1 linker histones. FASEB J 2001; 15:34-42.

45 Bates DL, Butler PJ, Pearson EC, Thomas JO. Stability of the higher-order structure of chicken-erythrocyte chromatin in solution. Eur J Biochem 1981; 119:469-476.

46 Woodcock CL, Skoultchi AI, Fan Y. Role of linker histone in chromatin structure and function: H1 stoichiometry and nucleosome repeat length. Chromosome Res 2006; 14:17-25.

47 Happel N, Doenecke D. Histone H1 and its isoforms: contribution to chromatin structure and function. Gene 2009; 431:1-12.

48 Allan J, Staynov DZ, Gould H. Reversible dissociation of linker histone from chromatin with preservation of internucleosomal repeat. Proc Natl Acad Sci USA 1980; 77:885-889.

49 Clore GM, Gronenborn AM, Nilges M, Sukumaran DK, Zarbock J. The polypeptide fold of the globular domain of histone $\mathrm{H} 5$ in solution. A study using nuclear magnetic resonance, distance geometry and restrained molecular dynamics. EMBO $J$ 1987; 6:1833-1842.

50 Graziano V, Gerchman SE, Wonacott AJ, et al. Crystallization of the globular domain of histone H5. J Mol Biol 1990; 212:253-257.

51 Ramakrishnan V, Finch JT, Graziano V, Lee PL, Sweet RM. Crystal structure of globular domain of histone H5 and its implications for nucleosome binding. Nature 1993; 362:219-223.

52 Thomas JO, Rees C, Finch JT. Cooperative binding of the globular domains of histones $\mathrm{H} 1$ and H5 to DNA. Nucleic Acids Res 1992; 20:187-194.

53 Krylov D, Leuba S, van Holde K, Zlatanova J. Histones H1 and $\mathrm{H} 5$ interact preferentially with crossovers of double-helical DNA. Proc Natl Acad Sci USA 1993; 90:5052-5056.

54 Varga-Weisz P, van Holde K, Zlatanova J. Preferential binding of histone H1 to four-way helical junction DNA. J Biol Chem 1993; 268:20699-20700.

55 Hayes JJ, Wolffe AP. Preferential and asymmetric interaction of linker histones with 5S DNA in the nucleosome. Proc Natl Acad Sci USA 1993; 90:6415-6419.

56 An W, Leuba SH, van Holde K, Zlatanova J. Linker histone protects linker DNA on only one side of the core particle and in a sequence-dependent manner. Proc Natl Acad Sci USA 1998; 95:3396-3401. 
57 An W, van Holde K, Zlatanova J. Linker histone protection of chromatosomes reconstituted on 5S rDNA from Xenopus borealis: a reinvestigation. Nucleic Acids Res 1998; 26:40424046.

58 Hayes JJ, Pruss D, Wolffe AP. Contacts of the globular domain of histone H5 and core histones with DNA in a "chromatosome”. Proc Natl Acad Sci USA 1994; 91:7817-7821.

59 Noll M, Kornberg RD. Action of micrococcal nuclease on chromatin and the location of histone H1. J Mol Biol 1977; 109:393-404.

60 Thoma F, Koller T. Influence of histone H1 on chromatin structure. Cell 1977; 12:101-107.

61 Hansen JC, Ausio J, Stanik VH, van Holde KE. Homogeneous reconstituted oligonucleosomes, evidence for salt-dependent folding in the absence of histone H1. Biochemistry 1989; 28:9129-9136.

62 Bednar J, Horowitz RA, Dubochet J, Woodcock CL. Chromatin conformation and salt-induced compaction: three-dimensional structural information from cryoelectron microscopy. $J$ Cell Biol 1995; 131:1365-1376.

63 Hamiche A, Schultz P, Ramakrishnan V, Oudet P, Prunell A. Linker histone-dependent DNA structure in linear mononucleosomes. J Mol Biol 1996; 257:30-42.

64 Bednar J, Horowitz RA, Grigoryev SA, et al. Nucleosomes, linker DNA, and linker histone form a unique structural motif that directs the higher-order folding and compaction of chromatin. Proc Natl Acad Sci USA 1998; 95:14173-14178.

65 Zlatanova J, Leuba SH, van Holde K. Chromatin fiber structure: morphology, molecular determinants, structural transitions. Biophys $J$ 1998; 74:2554-2566.

66 Allan J, Hartman PG, Crane-Robinson C, Aviles FX. The structure of histone $\mathrm{H} 1$ and its location in chromatin. Nature 1980; 288:675-679.

67 Allan J, Mitchell T, Harborne N, Bohm L, Crane-Robinson C. Roles of $\mathrm{H} 1$ domains in determining higher order chromatin structure and H1 location. J Mol Biol 1986; 187:591-601.

68 Subirana JA. Analysis of the charge distribution in the Cterminal region of histone $\mathrm{H} 1$ as related to its interaction with DNA. Biopolymers 1990; 29:1351-1357.

69 Churchill ME, Travers AA. Protein motifs that recognize structural features of DNA. Trends Biochem Sci 1991; 16:92-97.

$70 \mathrm{Lu} \mathrm{X}$, Hansen JC. Identification of specific functional subdomains within the linker histone $\mathrm{H} 10 \mathrm{C}$-terminal domain. $J$ Biol Chem 2004; 279:8701-8707.

71 Hansen JC, Lu X, Ross ED, Woody RW. Intrinsic protein disorder, amino acid composition, and histone terminal domains. J Biol Chem 2006; 281:1853-1856.

72 Lu X, Hamkalo B, Parseghian MH, Hansen JC. Chromatin condensing functions of the linker histone $\mathrm{C}$-terminal domain are mediated by specific amino acid composition and intrinsic protein disorder. Biochemistry 2009; 48:164-172.

73 Dunker AK, Brown CJ, Lawson JD, Iakoucheva LM, Obradovic Z. Intrinsic disorder and protein function. Biochemistry 2002; 41:6573-6582.

74 Wright PE, Dyson HJ. Intrinsically unstructured proteins: reassessing the protein structure-function paradigm. $J$ Mol Biol 1999; 293:321-331.

75 Clark DJ, Hill CS, Martin SR, Thomas J O. Alpha-helix in the carboxy-terminal domains of histones $\mathrm{H} 1$ and H5. EMBO J
1988; 7:69-75.

76 Bradbury EM, Cary PD, Chapman GE, et al. Studies on the role and mode of operation of the very-lysine-rich histone $\mathrm{H} 1$ (F1) in eukaryote chromatin. The conformation of histone H1. Eur J Biochem 1975; 52:605-613.

77 Vila R, Ponte I, Collado M, Arrondo JL, Suau P. Induction of secondary structure in a $\mathrm{COOH}$-terminal peptide of histone $\mathrm{H} 1$ by interaction with the DNA: an infrared spectroscopy study. $J$ Biol Chem 2001; 276:30898-30903.

78 Vila R, Ponte I, Jimenez MA, Rico M, Suau P. A helix-turn motif in the C-terminal domain of histone H1. Prot Sci 2000; 9:627-636.

79 Roque A, Ilboro I, Arrondo JL, Suau P. DNA-induced secondary structure of the carboxyl-terminal domain of histone H1. $J$ Biol Chem 2005; 280:32141-32147.

80 Ni JQ, Liu LP, Hess D, Rietdorf J, Sun FL. Drosophila ribosomal proteins are associated with linker histone H1 and suppress gene transcription. Genes Dev 2006; 20:1959-1973.

81 Lykke-Andersen J. mRNA quality control: marking the message for life or death. Curr Biol 2001; 11:R88-R91.

82 Krecic AM, Swanson MS. hnRNP complexes: composition, structure, and function. Curr Opin Cell Biol 1999; 11:363-371.

$83 \mathrm{Kim} \mathrm{K}$, Choi J, Heo K, et al. Isolation and characterization of a novel H1.2 complex that acts as a repressor of p53-mediated transcription. J Biol Chem 2008; 283:9113-9126.

84 Kraus WL. Transcriptional control by PARP-1: chromatin modulation, enhancer-binding, coregulation, and insulation. Curr Opin Cell Biol 2008; 20:294-302.

85 Kohno K, Izumi H, Uchiumi T, Ashizuka M, Kuwano M. The pleiotropic functions of the Y-box-binding protein, YB-1. Bioessays 2003; 25:691-698.

86 White MK, Johnson EM, Khalili K. Multiple roles for Puralpha in cellular and viral regulation. Cell Cycle 2009; 8:1-7.

87 Widlak P, Garrard WT. Discovery, regulation, and action of the major apoptotic nucleases DFF40/CAD and endonuclease G. $J$ Cell Biochem 2005; 94:1078-1087.

88 Widlak P, Garrard WT. Roles of the major apoptotic nucleaseDNA fragmentation factor-in biology and disease. Cell Mol Life Sci 2009; 66:263-274.

89 Liu X, Li P, Widlak P, et al. The 40-kDa subunit of DNA fragmentation factor induces DNA fragmentation and chromatin condensation during apoptosis. Proc Natl Acad Sci USA 1998; 95:8461-8466.

90 Widlak P, Lanuszewska J, Cary RB, Garrard WT. Subunit structures and stoichiometries of human DNA fragmentation factor proteins before and after induction of apoptosis. $J$ Biol Chem 2003; 278:26915-26922.

91 Liu X, Zou H, Widlak P, Garrard W, Wang X. Activation of the apoptotic endonuclease DFF40 (caspase-activated DNase or nuclease). Oligomerization and direct interaction with histone H1. J Biol Chem 1999; 274:13836-13840.

92 Woo EJ, Kim YG, Kim MS, et al. Structural mechanism for inactivation and activation of CAD/DFF40 in the apoptotic pathway. Mol Cell 2004; 14:531-539.

93 Widlak P, Li P, Wang X, Garrard WT. Cleavage preferences of the apoptotic endonuclease DFF40 (caspase-activated DNase or nuclease) on naked DNA and chromatin substrates. $J$ Biol Chem 2000; 275:8226-8232.

94 Widlak P, Kalinowska M, Parseghian MH, Lu X, Hansen JC, 
Garrard WT. The histone H1 C-terminal domain binds to the apoptotic nuclease, DNA fragmentation factor (DFF40/CAD) and stimulates DNA cleavage. Biochemistry 2005; 44:78717878 .

95 Montes de Oca R, Lee KK, Wilson KL. Binding of barrier to autointegration factor (BAF) to histone $\mathrm{H} 3$ and selected linker histones including H1.1. J Biol Chem 2005; 280:42252-42262.

96 Vila R, Ponte I, Collado M, et al. DNA-induced alpha-helical structure in the NH2-terminal domain of histone H1. J Biol Chem 2001; 276:46429-46435.

97 Lee H, Habas R, Abate-Shen C. MSX1 cooperates with histone $\mathrm{H} 1 \mathrm{~b}$ for inhibition of transcription and myogenesis [see comment]. Science 2004; 304:1675-1678.

98 Nielsen AL, Oulad-Abdelghani M, Ortiz JA, Remboutsika E, Chambon P, Losson R. Heterochromatin formation in mammalian cells: interaction between histones and HP1 proteins. Mol Cell 2001; 7:729-739.

99 Daujat S, Zeissler U, Waldmann T, Happel N, Schneider R. HP1 binds specifically to Lys26-methylated histone H1.4, whereas simultaneous Ser27 phosphorylation blocks HP1 binding. J Biol Chem 2005; 280:38090-38095.

100 Karetsou Z, Sandaltzopoulos R, Frangou-Lazaridis M, et al. Prothymosin alpha modulates the interaction of histone $\mathrm{H} 1$ with chromatin. Nucleic Acids Res 1998; 26:3111-3118.

101 Godde JS, Ura K. Cracking the enigmatic linker histone code. J Biochem 2008; 143:287-293.

102Hohmann P. Phosphorylation of H1 histones. Mol Cell Biochem 1983; 57:81-92.

103 Talasz H, Helliger W, Sarg B, Debbage PL, Puschendorf B, Lindner H. Hyperphosphorylation of histone H2A.X and dephosphorylation of histone H1 subtypes in the course of apoptosis. Cell Death Differ 2002; 9:27-39.

104Horn PJ, Carruthers LM, Logie C, et al. Phosphorylation of linker histones regulates ATP-dependent chromatin remodeling enzymes. Nat Struct Biol 2002; 9:263-267.

105 Guo CY, Mizzen C, Wang Y, Larner JM. Histone H1 and H3 dephosphorylation are differentially regulated by radiationinduced signal transduction pathways. Cancer Res 2000; 60:5667-5672.

106Phram AD, Sauer F. Ubiquitin-activating/conjugating activity of TAFII250, a mediator of activation of gene expression in Drosophila [see comment]. Science 2000; 289:2357-2360.

107 Wisniewski JR, Zougman A, Kruger S, Mann M. Mass spectrometric mapping of linker histone $\mathrm{H} 1$ variants reveals multiple acetylations, methylations, and phosphorylation as well as differences between cell culture and tissue. Mol Cell Proteomics 2007; 6:72-87.

108 Wood C, Snijders A, Williamson J, Reynolds C, Baldwin J, Dickman M. Post-translational modifications of the linker histone variants and their association with cell mechanisms.
FEBS J 2009; 276:3685-3697.

109 Vaquero A, Scher M, Lee D, Erdjument-Bromage H, Tempst P, Reinberg D. Human SirT1 interacts with histone H1 and promotes formation of facultative heterochromatin. Mol Cell 2004; 16:93-105.

110 Papamarcaki T, Tsolas O. Prothymosin alpha binds to histone H1 in vitro. FEBS Lett 1994; 345:71-75.

111 Gasser R, Koller T, Sogo JM. The stability of nucleosomes at the replication fork. J Mol Biol 1996; 258:224-239.

112 Swindle CS, Engler JA. Association of the human papillomavirus type 11 E1 protein with histone H1. J Virol 1998; 72:1994-2001.

113 Giampuzzi M, Oleggini R, Di Donato A. Demonstration of in vitro interaction between tumor suppressor lysyl oxidase and histones $\mathrm{H} 1$ and $\mathrm{H} 2$ : definition of the regions involved. Biochim Biophys Acta 2003; 1647:245-251.

114 Rasmussen C, Garen C. Activation of calmodulin-dependent enzymes can be selectively inhibited by histone H1. J Biol Chem 1993; 268:23788-23791.

115 Erard MS, Belenguer P, Caizergues-Ferrer M, Pantaloni A, Amalric F. A major nucleolar protein, nucleolin, induces chromatin decondensation by binding to histone H1. Eur J Biochem 1988; 175:525-530.

116Erard M, Lakhdar-Ghazal F, Amalric F. Repeat peptide motifs which contain beta-turns and modulate DNA condensation in chromatin. Eur J Biochem 1990; 191:19-26.

117 Zhao M, Sutherland C, Wilson DP, Deng J, Macdonald JA, Walsh MP. Identification of the linker histone $\mathrm{H} 1$ as a protein kinase Cepsilon-binding protein in vascular smooth muscle. Biochem Cell Biol 2004; 82:538-546.

118 Kohlstaedt LA, Cole RD. Specific interaction between H1 histone and high mobility protein HMG1. Biochemistry 1994; 33:570-575.

119Finn RM, Browne K, Hodgson KC, Ausio J. sNASP, a histone H1-specific eukaryotic chaperone dimer that facilitates chromatin assembly. Biophys J 2008; 95:1314-1325.

120 Wang H, Walsh ST, Parthun MR. Expanded binding specificity of the human histone chaperone NASP. Nucleic Acids Res 2008; 36:5763-5772.

121 Cerf C, Lippens G, Ramakrishnan V, et al. Homo- and heteronuclear two-dimensional NMR studies of the globular domain of histone H1: full assignment, tertiary structure, and comparison with the globular domain of histone H5. Biochemistry 1994; 33:11079-11086.

122Emsley P, Cowtan K. Coot: model-building tools for molecular graphics. Acta Crystallogr D Biol Crystallogr 2004; 60:21262132 .

123Humphrey W, Dalke A, Schulten K. VMD: Visual molecular dynamics. J Mol Graphics 1996; 14:33-38, 27-28. 